Teknokultura. Revista de Cultura Digital y Movimientos Sociales

ISSNe: $1549-2230$

https://dx.doi.org/10.5209/TEKN.69454

\title{
Mecanismos de explotación en el capitalismo digital. Modos de plusvalía en red $^{1}$
}

Rafael Rodríguez Prieto ${ }^{2}$

Recibido: 13 de mayo de 2020 / Aceptado: 8 de julio de 2020 Open peer reviews

Resumen. El pensamiento materialista nos ha dotado de herramientas muy útiles para el análisis de los procesos sociales. La plusvalía ha sido uno de los hallazgos más relevantes al desvelar los procedimientos de acumulación del capital y la explotación. En la actualidad, la plusvalía se ha ido transformado y adaptando a un 'nuevo territorio virtual' que ofrece Internet. En este artículo se distinguen dos modos de plusvalía en Red. Se analizan tanto aquella que procede de los datos y su expresión, especialmente, en las redes sociales y aquella que se obtiene gracias a la economía colaborativa. El artículo propone no solo su identificación y crítica, sino el uso de la producción socialmente útil y, por tanto, la democratización de la producción como herramientas para contrarrestarlas.

Palabras clave: democracia; economía colaborativa; producción; redes sociales.

\section{[en] Exploitation mechanisms in digital capitalism. Network surplus modes}

\begin{abstract}
Materialistic thinking has provided us with very useful tools for the analysis of social processes. Surplus has been one of the most relevant findings in revealing the procedures for capital accumulation and exploitation. Nowadays, the surplus value has been transformed and adapted to a new 'virtual territory' offered by the Internet. This article distinguishes two modes of network surplus value. Those that come from the data and their expression, especially on social networks are analized as are those obtained thanks to the collaborative economy. The paper proposes not only its identification and criticism, but the use of socially useful production and, therefore, the democratization of production as tools to counter them.
\end{abstract}

Keywords: collaborative economy; democracy; production; social network.

Sumario. 1. Introducción. 2. Mecanismos de explotación en el capitalismo digital. 3. Modos de plusvalía en Red. 4. La plusvalía en Red vs producción socialmente útil. 5. Conclusiones. 6. Referencias.

Cómo citar: Rodríguez Prieto, R. (2020). Mecanismos de explotación en el capitalismo digital. Modos de plusvalía en red. Teknokultura. Revista de Cultura Digital y Movimientos Sociales, 17(2), 131-140.

\section{Introducción}

En el último capítulo del primer volumen de El Capital, Marx señala que la primera acumulación de capital se logró gracias al saqueo y la violencia que este lleva aparejado (Marx, 1977). Las endémicas crisis de este modelo de producción precisan de cíclicos saltos adelante, es decir nuevas acumulaciones. Cuando se observa el desarrollo de Internet, no es difícil apreciar ese saqueo del procomún, acompañado de una privatización de territorios comunales. Ese denodado rigor acumulativo parece estar atado a una fuerte regresión en los derechos individuales. Veamos cómo justificar estas afirmaciones.

No faltan noticias que nos advierten de que los dispositivos electrónicos nos espían. Siri, el asistente de voz de Apple, es el último ejemplo de un aparato cuya funcionalidad puede ser discutible, pero cuya capacidad de vigilarnos está fuera de duda. En abril de 2020, el Centro Criptológico Nacional advirtió que personal externo a Apple tiene acceso a las conversaciones que el Siri graba. No es la primera vez que algo así sucede, ni la primera empresa que lo hace. Si usamos un teléfono 'inteligente' vamos a tener la opción de dar una orden con nuestra voz. Es más, se nos anima a que lo hagamos. Al colaborar con estas grandes empresas quizá podemos satisfacer nuestro ego, pero deberíamos ser conscientes que les estamos ayudando a mejorar sus productos de forma absolutamente altruista. En realidad, estamos cediendo datos personales muy valiosos en el mercado $\mathrm{y}$, en ciertas ocasiones, facilitando la posibilidad de ser espiados y, por tanto, controlados.

\footnotetext{
Investigación desarrollada al amparo del Proyecto del Plan Nacional de I D I (Ref.: DER2015-65906-P).

2 Universidad Pablo de Olavide (España).

E-mail: rrodpri@upo.es
} 
El Fiscal General de Nuevo México acusó a Google de espiar a millones de niños y a sus familias en Estados Unidos y España con 'propósitos oscuros' en febrero de 2020. Este argumento pudiera resumirse en el almacenamiento y procesamiento de información personal de su actividad en Internet, así como incluso grabaciones de voz o contraseñas. De ser ciertas tales imputaciones, no habría ningún propósito educativo, tal y como sostiene la acusación. No es un asunto nuevo. En Cataluña, colectivos como Xnet advirtieron de los riesgos del uso de Google Suite en las escuelas, sin que la autoridad competente les prestara la más mínima atención.

La escuela se puede transformar en un vivero de datos para una megaempresa transnacional y nuestros hijos en meros objetos que generan miles de millones de dólares en datos. Las responsabilidades son varias y de distinto grado. Por un lado, el gigante tecnológico y empresarial. De ser ciertas tales actividades, estaríamos ante un comportamiento delictivo. En consecuencia, tendrían el más alto grado de responsabilidad. Desde una perspectiva moral, sería un comportamiento sumamente repudiable, por tratarse de explotación de menores. Pero hay más responsables. Las autoridades educativas tienen el deber de velar por la seguridad de aquellos que están a su cargo durante varias horas al día. Ocultarse bajo el paraguas del desconocimiento no debería servirles para eludir su responsabilidad. Si las administraciones públicas no conocen los riesgos, existen multitud de expertos que pueden alertarlos. En tercer lugar estarían los padres. Cierto es que depositan su confianza en la administración educativa, pero también que, en demasiados casos, regalan a su hijo de 10 años un teléfono inteligente con un sistema operativo controlado por grandes empresas y con acceso a Internet.

No es difícil percibir que uno de los mayores problemas que tienen, en general, las sociedades es banalizar el uso de Internet, junto con su desconocimiento. La noción de lo 'gratis' es el ejemplo más significativo. Consecuencia de esta falsa idea y la aculturación de las generaciones de ciudadanos en labores que conducen a la supresión de puestos de trabajo, ha sido un alza brutal en los beneficios de empresas que, especialmente en el sector de la Red, se han convertido en las primeras del mundo por capitalización. Nuestra hipótesis es que la hibridación entre los procesos conducentes a una transferencia masiva de rentas del trabajo a las de capital, denominado neoliberalismo, y el surgimiento de los gigantes como Google, Facebook o Amazon ha supuesto el desarrollo de un nuevo tipo de explotación y nuevas formas de obtención de plusvalía. Se debe advertir que el capitalismo se sostiene sobre la explotación. La denominación neoliberalismo o neoliberal no debiera entenderse como una forma de desviar la atención sobre el problema real -el capitalismo-, sino más bien como una forma de referirnos a la más reciente mutación o adaptación del capitalismo, como proceso sociocultural y económico, para sobrevivir y reproducirse.

Este trabajo analiza este mecanismo de explotación para luego estudiar la forma en que se materializa la obtención de plusvalía. Hay una plusvalía en Red -net surplus-que se obtiene de los datos y sus distintas formas de expresión en Internet. Otra plusvalía es aquella que procede de la economía colaborativa. Este tipo de plataformas virtuales ha generado ingentes cantidades de beneficio en los últimos años a los grandes inversores que facilitaron su puesta en marcha. Estos inversores habían ido a pérdidas, en sus inicios, porque sabían que su penetración en mercados ya existentes no sería fácil, de acuerdo con el país donde decidieran llevar a cabo su actividad mercantil. Esta actividad ya se había visto en el decidido y crucial apoyo de elementos relevantes del anarcocapitalismo a algunos social media como Facebook.

Estas actividades reducen las posibilidades del procomún y de fortalecer los procesos y tendencias encaminados a construir espacios libres, democráticos y de respeto. Internet podría impulsar el desarrollo de una producción socialmente útil, lo que constituiría la democratización de la producción. Tal y como atisbaron a finales de los 60 Baran y Sweezy (1980, p. 272) en su interesante ensayo sobre las tendencias monopolistas del capitalismo, "una parte cada vez mayor de la sociedad capitalista monopolista, es de acuerdo con las necesidad humanas genuinas, innecesaria, antieconómica y absolutamente destructiva".

El ejemplo de Google Suite nos ayuda a entender los nuevos mecanismos de explotación. Por un lado, están las corporaciones que tienen la mayor responsabilidad y que obtienen ingresos cuantiosos con plusvalías que además no tributan adecuadamente. Por otro, está la responsabilidad de los gobiernos que cada vez más asumen el papel de colaboradores necesarios con las grandes empresas tecnológicas tanto por acción como por omisión. Pero, en tercer lugar, está la ciudadanía que tiene un papel fundamental es esta lucha que acaece en el mundo virtual y que se traduce constantemente en el espacio no virtual. Explotación puede sonar a concepto abstracto en Internet. No obstante, parece concretarse con claridad cuando en plena crisis del COVID-19 el sindicato de riders anunciaba que Glovo había bajado la tarifa base por reparto de $2,5 €$ a $1,25 €$ o, incluso en algunas ciudades a 1 euro.

\section{Mecanismos de explotación en el capitalismo digital}

Hay dos lecciones que el capitalismo no se ha cansado de ofrecer. La primera es su plasticidad, su adaptabilidad, una extraordinaria capacidad de hacer de sus conflictos y contradicciones oportunidades para dar un salto adelante, una nueva acumulación. La segunda es más sencilla, menos académica, pero de una dimensión práctica innegable: nunca lo subestimes. Que todavía haya gente que lo haga es un fenómeno equiparable al terraplanismo, pero en los círculos de izquierda.

Internet no iba a ser una excepción. No es menos correcto que se abrieran expectativas que plantearan la posibilidad de que la Red fuera una plataforma para el desarrollo de alternativas productivas y en la que el trabajador podría apropiarse al fin de los medios de producción. La experiencia ha matizado estas ideas. Las iniciativas conducentes a democratizar la producción se han 
desarrollado, pero, a la vez, no han variado las formas tradicionales de extracción de plusvalía o se han ampliado, gracias a esta tecnología. Internet es un campo de batalla donde se reproduce la lucha de clases incardinada en procesos y tendencias liberadores o totalitarios; privatizadores o comunes. Esta lucha va camino de transformarse en guerra si las tendencias de vigilancia, control y liquidación de derechos fundamentales que se atisban con el COVID19 se consolidan. No se trata de ser apocalípticos o integrados, sino de entender, como hizo Eco a finales de los 60 en su análisis de la cultura popular, que el trabajar "en y por un mundo construido a la medida humana no implica adaptar al hombre a las condiciones de hecho, sino a partir de estas condiciones de hecho" (Eco, 1988, p. 15).

Internet ha contribuido a desarrollar modelos de negocio desconocidos hasta la fecha y a reconfigurar otros tradicionales. Las plusvalías que se han generado con estas operaciones han logrado que compañías nacidas a su amparo se hayan convertido en las primeras del mundo. Ese es un dato objetivo que manifiesta la importancia de Internet para el capitalismo. Pero, es más: la concentración del mercado que se ha producido en la Red hace que la venta de productos y servicios se haya concentrado y favorecido el aumento de plusvalía en grandes empresas y la desaparición de pequeños empresarios. No es casualidad que Amazon sea una de las compañías más importantes del mundo. La emergencia del COVID19 solo puede hacer crecer esta tendencia ante la previsible ruina de librerías independientes, por citar un ejemplo evidente.

Se pueden distinguir dos vías de extracción de plusvalía de la Red. Junto con ellas hay una tercera que no se separa de la forma tradicional, aunque debe ser, al menos, referida por conciliar la Red con un incremento de la plusvalía, gracias a la concentración empresarial, a la deslocalización, la desaparición de competencia y la apertura sin descanso del negocio. No hay armonía posible entre los seres humanos y las demandas del capitalismo 24/7 días a la semana (Crary, 2015). Internet se convierte en una plataforma comercial sin límites espaciales ni temporales en las que los dependientes somos nosotros mismos (por ejemplo, trasferencias bancarias, compra de alimentos o reservas de vuelos), lo que genera que sea el propio comprador el que pase a ser un 'empleado' cualificado del que suministra la mercancía o presta el servicio. Este proceso también tiene lugar en el mundo no virtual, existiendo una interacción y un aprendizaje entre ambos donde uno potencia a otro y viceversa. La nuevas generaciones se aculturan en esta idea 'hágalo usted mismo' tan conveniente para generar más plusvalía.

La primera es la que transforma al ser humano en una fuente de datos que es comercializable. El producto somos nosotros mismos, nuestra vida es una agregación de comportamientos y decisiones que son monetizables. $\mathrm{Su}$ desarrollo se ha realizado, en gran medida, aunque no única, en las redes sociales. La segunda sería mediante lo que se ha denominado, de forma errónea o interesada, economía colaborativa, cuyo desarrollo en los últimos años y efectos han sido espectaculares. No solo ha en- contrado nuevos nichos de negocio. Su principal virtud ha sido apropiarse de aquellos tradicionalmente ocupados por pequeños productores. El éxito del capitalismo de plataforma (Srnicek, 2016) ha supuesto hacer de la intermediación virtual un gran negocio. Las plataformas de intermediación de servicios como el taxi, los alojamientos o la comida a domicilio defienden que obedecen a la idea de facilitar el contacto entre particulares para algún fin. Se propone aprovechar los coches, los domicilios particulares o incluso las bicicletas con el fin de lucrarse o, como se decía en sus orígenes por ejemplo en el sector del alojamiento, tener 'una experiencia enriquecedora'. Estas plataformas generan controversia. Por un lado, sus partidarios consideran que benefician el tejido económico y a sus usuarios. Se entiende que ayuda a dinamizar sectores muy anquilosados, que disfrutan de una serie de privilegios que limitan la productividad y que condenan a los consumidores a servicios extremadamente rígidos o caros. Fomentan la libertad económica, el emprendimiento de uno mismo y la competitividad. Para sus detractores son solo una forma de precarizar y, en realidad de vulnerar la legislación, ya que no se trataría de una mera intermediación, como han dejado claro algunas resoluciones judiciales, tanto a nivel nacional como europeo. El Tribunal de Justicia de la UE en una sentencia de 20 diciembre de 2017 consideró que UberPop era una empresa de transporte y no una plataforma digital de intermediación entre viajeros, considerando "que un servicio de esta índole está excluido del ámbito de aplicación del artículo 56 TFUE, de la Directiva 2006/123 y de la Directiva 2000/31".

Estas dos formas de obtención de plusvalía o plusvalía en Red no implican que el capitalismo haya abandonado las demás. Es imprescindible realizar una matización. Sería incorrecto e ilusorio pensar que el modelo económico hegemónico ha abandonado las formas más convencionales o tradicionales de explotación. Se continúa explotando en las fábricas o precarizando en el sector servicios. Solo hay que observar la realidad española y del resto del mundo, especialmente en aquellos países donde la mano de obra es más barata o competitiva, en palabras de la propaganda neoliberal. En consecuencia, no se trata de analizar linealmente la realidad y simplificar los fenómenos sociales, sino de entenderlos como concreciones de un mismo modelo de producción.

Es una buena oportunidad para evocar a los clásicos, aunque sea de manera heterodoxa, quizá como a ella le hubiera gustado. Rosa Luxemburg en su obra más academicista atisba algo que, a pesar de todos los límites, errores u obsolescencia que le achaquemos, es de extraordinario valor: el capital precisa de ampliar sus mercados (Luxemburg, 1967). Pensemos en un enfoque espacial. Milton Santos, el gran geógrafo brasileño, nos decía que, bajo el imperativo del crecimiento y la expansión, la búsqueda de la escala se vuelve constante (Santos, 2000). Es una expansión ad intra y ad extra. La primera se centra en un brutal proceso de concentración y, por tanto, de eliminación de la competencia; la segunda en una ampliación de mercados hacia nuevos horizontes, hacia nuevas tierras. 
Una imagen que suelo usar es la revolución inglesa. Es un fértil periodo de ideas y también un momento crucial para el desarrollo de las relaciones de producción. Es un momento histórico crucial porque no solo se está jugando el futuro de la monarquía, como la historiografía conservadora y liberal asume y difunde; tampoco es meramente una guerra de religión. Es, sobre todo, y sin obviar por supuesto la importancia de los factores anteriores, una cuestión decisiva para el modelo de propiedad, individual o colectiva y el futuro de las tierras comunales (Harman, 2018).

Las grandes empresas de Internet se han visto beneficiadas por la regulación neoliberal auspiciadas por las teorías neocontractualistas de la justicia. La desregulación o, mejor dicho, regulación neoliberal ha generado que las tendencias registradas en otros mercados se vieran aceleradas en Internet, donde en poco tiempo nos hemos encontrado que verdaderos gigantes han acaparado más de dos tercios del mercado y generado plusvalías espectaculares. Estas mismas megacompañías han 'descubierto' para el capitalismo ingentes territorios. La falsa idea auspiciada por el aparato de propaganda neoliberal de un estado débil y limitado colisiona con la realidad. El estado neoliberal y su intervención en el mercado se ha incrementado (Hardt \& Negri, 1994) precisamente para apoyar la concentración empresarial, privatizar servicios públicos y establecer las bases que transfieran y debiliten aún más las rentas del trabajo en beneficio del capital y su sociedad de control.

Como Marx y Engels señalaron, el capitalismo está ligado de forma indisoluble a la crisis de superproducción y a una desigualdad estructural y necesaria (Marx y Engels, 2011). Luxemburg aporta herramientas para repensar el mundo actual. Su obra económica define el capitalismo como un sistema abierto en expansión constante. A pesar de sus límites, ligados a una comprensión reduccionista sobre la formación de los mercados -solo al exterior- los nuevos mercados pueden fructificar $a d$ intra en el seno de las economías nacionales, e, "incluso, en el interior de las casas de la gente y, de hecho, dentro de sus cerebros" (Mason, 2015, p. 62). Cuando hablamos de capitalismo, la cuestión decisiva es la generación de la plusvalía. Marx es el primero que da a la plusvalía su carácter histórico y característico del capitalismo; los siervos o esclavos son medios de producción; solo en el capitalismo se extrae plusvalía en función del tiempo de trabajo o la cualificación (Rodríguez, 2013).

Marx distinguió entre tecnología como medio de comunicación y tecnología como medio de producción; hoy esa distinción es borrosa, ya que la computadora en red significa una convergencia entre ambas (Fuchs, 2019). En el capitalismo digital esta convergencia es decisiva para el desarrollo tanto de mecanismos generativos de plusvalía como de control. Esta es la magnífica capacidad del capitalismo digital: se garantiza grandes plusvalías, a la vez que desarrolla mecanismos de control, gracias al procesamiento de datos, que anteriormente solo podían estar al alcance de los gobiernos.

Periódicamente, el capital se renueva con revoluciones tecnológicas que aumentan la productividad, abren mercados, superan tendencias al estancamiento y la ba- jada de la tasa de ganancia, destruyen viejas industrias, creando otras nuevas (Dyer-Witheford \& Matviyenko, 2019). Internet ha supuesto algo más que eso. Ha sido como encontrar un nuevo planeta. Los límites se diluían con la misma rapidez que lo hacían las regulaciones que lo contenían.

El capitalismo digital amplía exponencialmente las posibilidades de obtención de plusvalía. Aprovecha la eficiencia de los sistemas de correos, generados y desarrollados durante décadas por la iniciativa pública para trasladar mercancías al consumidor en tiempo record y sin moverse de casa. Utiliza los lazos sociales para generar millones de datos sobre los que se puede negociar. Se reconduce una actividad presuntamente colaborativa y altruista para constituir una fuente de beneficios y de precarización del trabajo. El trabajo cualificado de los usuarios o las rentas extraídas del propio usuario conforman un modelo cuya tendencia evidente es la eliminación de derechos sociales. El caso de Amazon es paradigmático en su lucha contra la sindicalización de los trabajadores. Las viejas y tradicionales pulsiones autoritarias del capitalismo se revisten del halo de progresismo que le otorga la popularización y penetración de la tecnología en las vidas de las personas.

El capitalismo cuenta con la capacidad de reformular cualquier proceso social, incluso a aquellos contrarios al mismo. El sueño de ciertos pioneros de la Red que entendían Internet como un espacio superador de la subordinación salarial, gracias a la creatividad y a unos medios de producción propios y fáciles de adquirir, se torna hoy en una aspiradora de plusvalía, donde empresas cada vez más grandes e influyentes pretenden controlar aún más porciones de la actividad económica, lo que decreta el fin del libre mercado (incluso en su formulación más ingenua) y la consolidación del abuso de posición dominante.

Juan Carlos Rodríguez recuerda una anotación de Benjamin de un comentario de Brecht sobre lo bueno malo que destroza las viejas cosas buenas; de no deslindar y analizar las nuevas cosas malas no podremos avanzar (Rodríguez, 2013). En una sociedad como la actual en la que se glorifica tanto lo joven como lo nuevo, merece la pena reflexionar sobre las cosas que no estaban del todo mal antes de esta explosión tecnológica y todo lo que no está del todo bien después de ella.

\section{Modos de plusvalía en Red}

Aun desconocemos qué impacto tendrá el COVID-19 en nuestras sociedades. No han faltado analistas, sin embargo, para adelantar tanto escenarios postapocalípticos como emancipadores y es muy probable que en los próximos meses nos encontremos con una oleada de textos afines. Si algo muestran los procesos anteriores es que es imprescindible un cierto grado de precaución y cautela. Con la crisis de 2008 no faltaron estamentos oficiales, fuertemente comprometidos con el capital, que realizaron sorprendentes discursos que hablaban de la necesaria 'refundación del capitalismo' o de aprender de los 'errores de la crisis', refiriéndose a los instrumentos 
financieros que, en parte, condujeron a la misma. Pocos meses después no quedaba nada. Lo único que permaneció fue la impresión de que la sociedad aun no estaba muerta; que argumentos tales como el apoyo mutuo, la defensa del estado social y la democracia seguían vivos en el imaginario colectivo, gracias a las prácticas pedagógicas que ocuparon, durante días, plazas y en las que España fue ejemplo mundial. En consecuencia, seamos cautelosos. Entendamos que esta crisis ya está teniendo ganadores y perdedores dentro del propio capitalismo.

Entre los ganadores estarían negocios como Amazon, emisores de tarjetas de crédito, financieros que especulan con posiciones en corto, compañías como Glovo o Deliveroo. Es decir, que esta crisis puede reforzar posiciones de empresas de la Red que ya partían antes con una ventaja competitiva muy importante y, al mismo tiempo, arruinar a pequeños productores (aunque no sea descartable que caigan empresas de mayor tamaño). Esta no es la principal razón para que analicemos con mayor profundidad estos modos de extracción de plusvalía en Red.

Se ha de tener en consideración que es muy probable que los mecanismos de control y disciplina capitalista se intensifiquen para minimizar los riesgos de revueltas sociales. Lo lógico será que el big data sea usado tanto por compañías privadas como por los gobiernos. Las primeras pueden utilizar esa información para negociar posiciones ventajosas con los segundos. De hecho, se mandan, de forma cíclica, mensajes a la opinión pública donde se apuesta por apps que ejerzan un control estricto sobre la población a propósito del COVID-19, a pesar de que pueda suponer una vulneración de derechos fundamentales. Son apps en las que además participan empresas privadas. Incluso se llega a mostrar como ejemplos a estados totalitarios como China en el control de la enfermedad y en el uso de esta tecnología. Corea del Sur, un país asentado sobre un nacionalismo de corte etnicista al que se suele también poner de ejemplo, es un país con un fuerte estado policial que establece profundas restricciones a la democracia.

Todo este escenario genera más preguntas que respuestas. La fuerza de trabajo posfordista ligada a la emergencia de una subjetividades identificadas por algunos autores como de 'obrero social' desarrolla la cooperación productiva y, se pensó, que haría posible, gracias a su capacidad de innovar en redes y su habilidad para tomar decisiones en común, la democracia (Hardt y Negri, 2004). Esta idea merecería matizarse. Es cierto que la socialización extralaboral como aquella de la cual se beneficia la industria cultural o la de alta tecnología, desarrolla nuevas y flexibles formas de valorización del capital, pero se encuentran absolutamente ligadas a su proceso de acumulación (Virno, 2003) y todo ello teniendo en consideración que la influencia del trabajo inmaterial es mayor en estados con una posición más relevante en la esfera global.

Hoy es fácil entender que algunas valoraciones posfordistas, en concreto las demasiado optimistas, subestimaron la potencia del capital. La capacidad de desarrollar formas de reconducir las potencias colectivas y los procesos en común no es nueva. No obstante, la capacidad de extraer una plusvalía que nutra la emergencia de gigantes tecnológicos que pueden mirar a cara a cara a los estados con más peso en la comunidad internacional, sí lo es.

\subsection{Monetización de las relaciones humanas. Deshumanización y plusvalía en Red}

En 2016 algunos ilustres youtubers mostraron su enfado con la empresa de vídeos a consecuencia de un correo recibido en el que se les calificaba sus contenidos como 'no familiares' y, por tanto, no elegibles para monetización. Cuando estos usuarios leyeron las condiciones que podían afectar a sus vídeos, se dieron cuenta tanto de su amplitud como de su vaguedad - subjects related to political conflicts-. En septiembre de 2016 la política de la compañía cambió en 'aras de la transparencia'. Aquellos usuarios cuyo vídeos fueran desmonetizados recibirían un correo electrónico en el que se les informaría de su situación. La revisión de las condiciones del servicio en junio de 2016, junto con la calificación de ad-friendly ha ocasionado una relevante protesta contra YouTube. Desde 2012 YouTube ha desmonetizado contenido inapropiado para los anunciantes.

Estas prácticas se han realizado de forma automatizada, lo que también ha ocasionado que, a veces, se desmonetizaran vídeos que no habían incumplido los términos y condiciones de uso. De hecho, el algoritmo que controla esta función actúa de forma automática. Si el usuario recibe el correo y protesta, la revisión puede llevar tiempo, con lo que perdería cuantiosos ingresos si se tratara de un vídeo viral. Esta cuestión es diferente de la práctica que realiza YouTube de eliminar cualquier material que pudiera infringir sus términos y condiciones de uso, en lo referido al material que es aceptable subir a la plataforma. Por ejemplo, cualquier vídeo que pudiera infringir la legislación de propiedad intelectual o fuera de contenido pornográfico. Al apropiarse del valor de lo ya producido, la persona que cooperó con la empresa, que posteriormente le censura, no puede recuperar el trabajo ya realizado, del que la empresa se ha beneficiado y se beneficiará (visitas o rendimientos futuros, por ejemplo). Por otra parte, debido a las draconianas condiciones de los contratos de adhesión para la creación de perfiles en este tipo de servicios, el usuario cede la gestión de los derechos de sus creaciones a la compañía (Rodríguez, 2019).

Estamos ante una dinámica que incluye y desborda el denominado 'capitalismo de plataforma', vinculado a la economía falsamente colaborativa, donde se usa la Red para extraer beneficio de sectores que han estado tradicionalmente muy regulados por las administraciones públicas. También implica un cambio frente a la noción tradicional de plusvalía, vinculada a relaciones asalariadas donde el control del tiempo en el centro de trabajo era el elemento decisivo. Gracias a Internet se logra extraer beneficio de fuentes que superan la relación laboral. Se produce una deslocalización extrema que mercantiliza relaciones sociales de forma radical y se transforman en materia prima sobre la que se negocia. 
Una mera conversación entre personas se convierte en una fuente de datos con el que un tercero privado extrae plusvalía (por ejemplo, cuando se abre un hilo en Twitter y se establece una interacción con otros usuarios). El rastro que las personas dejan en la Red genera unos contenidos sobre los que se extrae plusvalía. Tanto cuando se suben vídeos a Youtube, como cuando modifican sus páginas de Facebook - por poner dos ejemplos cotidianos- se generan datos, cuyo tratamiento se convierte en ganancia.

La acumulación del capital depende de la realización de la plusvalía. El capitalismo precisa evitar que descienda, ya que su supervivencia depende de ello. Es más: los beneficios regulares, en el capitalismo, son destruidos periódicamente a causa de que la crisis es endémica a este modelo de producción; su única cura es la inyección periódica de capital preliminar, es decir, saltos adelante del modelo. La plusvalía en Red es consecuencia de un excedente de valor que aporta el internauta de forma consciente o inconsciente. Es una forma contemporánea de la plusvalía tradicional. Se trata de una transferencia ingente de recursos al capital, por la razón de que el trabajo que realiza no suele ser su fuente principal de ingresos, por lo que no está tan alerta, además de la presión para estar siempre conectado. Es también una plusvalía que se extrae de la propia personalidad del usuario, en forma de datos o donde este obtiene, a cambio del acceso a una red social, una retribución en prestigio o una ridícula compensación en términos monetarios. Las técnicas de procesamiento, almacenamiento y análisis de datos -el denominado big data-, junto a los ingresos por publicidad o la monetización de contribuciones altruistas permiten a las grandes empresas de la Red extraer recursos de actividades sociales que antes quedaban fuera de la esfera de lo mercantil y por la que pagan impuestos ridículos. Los likes, preferencias o fotos son una materia prima muy valiosa.

El valor creado por este plustrabajo (materializado en un plusservicio o plusproducto) es la plusvalía apropiada de forma gratuita por las grandes corporaciones de Internet. Marx y sus seguidores señalaron que el aumento de la tasa de explotación consistía en aumentar la jornada de trabajo al trabajador o bien que el trabajador produjera más en el mismo tiempo o, incluso, lo mismo en menos tiempo (Rodríguez y Martínez, 2016). En el caso de Internet, gracias a la mitificación de todo lo que tiene que ver con la Red, y con la decisiva influencia de los grandes del sector, se ha constituido un ejército de reserva efectivo de internautas que se prestan a facilitar trabajo gratis en condiciones propias de la revolución industrial. El nivel de los que aceptan este tipo de condiciones es muy variable. Desde el adolescente que contribuye con datos propios o con un vídeo, hasta el doctor universitario que trabaja gratis para Google Scholar.

Durante el COVID19 se ha incrementado el uso de Internet, $y$, en consecuencia, el rastro digital de la ciudadanía. Grupos de whatsapp, búsquedas en Google sobre el virus, comunicación virtual a través de Facebook o Instagram con las personas que vemos a diario, descarga de películas y series en plataformas digitales como HBO o Netflix y satisfacción de la pulsión compradora en Amazon o comida, preparada o no, a través Glovo o el Corte Inglés, y teletrabajo. El confinamiento puede tener un efecto de acelerada aculturación en aquellas generaciones que no lo estaban. Y, justamente, en este proceso, los gigantes del sector están acumulando y procesando ingentes cantidades de datos vinculados a preferencias, comportamientos y opiniones que monetizarán utilizando vías diversas; es decir, han convertido los rastros de nuestro confinamiento en una gran plantación o una gran fábrica de la que extraerán plusvalía en Red, no sujetas a tributación real, como muestran los desesperados y estériles esfuerzos, hasta la fecha, por parte de gobiernos europeos de generar un mecanismo tributario que les ayude a recibir una porción mínima de este negocio. Los mismos que han tolerado la existencia de paraísos fiscales, se encuentran hoy con unas empresas capaces de exonerarse unilateralmente del pago efectivo de impuestos.

\subsection{La falsa economía colaborativa}

La sentencia 188/2019 del juzgado de lo social de Madrid de 22 de julio de 2019 contrasta en su fundamento de derecho sexto "la falta de una organización empresarial en un sentido mínimamente estricto de los repartidores aisladamente considerados", con el hecho probado de que los trabajadores han realizado un trabajo personal sometido a la dirección de una empresa "que es la única que controla la marca Deliveroo, su aplicación informática y toda la información que se desprende de ella".

Esta sentencia ejemplifica muy bien lo que, en realidad, es la falsa economía colaborativa; un 'capitalismo de plataforma', que, gracias a la tecnificación y la traducción de esta en un entorno neoliberal de desregulación, ha favorecido la aparición de operadores muy agresivos. Su perfil suele responder a empresas con una fuerte financiación (inyecciones de dinero de fondos capital riesgo o gigantes tecnológicos como Amazon o Alphabet), cuyos inversores incluso aceptan pérdidas en los primeros años (López, 2019), eluden el pago de impuestos en los estados en los que actúan (los servicios de la sociedad de la información regulados por la Directiva 2000/31/CE se regirán por la legislación del Estado de establecimiento del prestador, así Airbnb se estableció en Irlanda y Uber en Holanda) e irrumpen en sectores tradicionales, a menudo bastante regulados. Algunos autores se refieren a esta economía como capitalismo de plataforma de una forma pretendidamente más aséptica con el fin de calificar los sucesivos cambios que la digitalización ha generado en el modelo productivo (Srnicek. 2016). La cuestión esencial es dilucidar si la labor de intermediación es tal, o solo la forma en que la que estas empresas pueden extraer plusvalía (con carácter general, se aplica la Ley 34/2002, de 11 de julio, de servicios de la sociedad de la información y de comercio electrónico. Inicialmente, la categoría de servicios de la sociedad de la información aparece en la Directiva 2000/31/CE que se transpuso por la ley anteriormente citada de 
2002). Los datos y las evidencias desmontan la mitología del garaje y del self made man. Lejos de ser una aventura romántica de unos cuantos emprendedores, en la mayoría de los casos son proyectos fuertemente respaldados por entidades o individuos con una alta capacidad inversora.

La Agenda Europea para la economía colaborativa (2.6.2016) de la Comisión Europea planteó un conjunto de directrices para su desarrollo. La UE estimó que "estos nuevos modelos de negocio pueden aportar una importante contribución al crecimiento y el empleo en la Unión Europea si se fomentan y desarrollan de forma responsable". Se define esta economía como "modelos de negocio en los que se facilitan actividades mediante plataformas colaborativas que crean un mercado abierto para el uso temporal de mercancías o servicios ofrecidos a menudo por particulares. La economía colaborativa implica a tres categorías de agentes i) prestadores de servicios que comparten activos, recursos, tiempo y/o competencias - pueden ser particulares que ofrecen servicios de manera ocasional ('pares') o prestadores de servicios que actúen a título profesional ('prestadores de servicios profesionales'); ii) usuarios de dichos servicios; y iii) intermediarios que -a través de una plataforma en líneaconectan a los prestadores con los usuarios y facilitan las transacciones entre ellos ('plataformas colaborativas'). Por lo general, las transacciones de la economía colaborativa no implican un cambio de propiedad y pueden realizarse con o sin ánimo de lucro".

El propósito de este modelo comercial es compartir bienes y servicios. Una economía de compartir o sharing economy vinculada a conceptos como On-Demand Workforce (Sundararajan, 2017, p. 10). El problema surge cuando apreciamos la indeterminación y vaguedad de los conceptos usados y la apelación a algo tan aparentemente solidario, ecológico o, incluso, emancipador, como sería 'compartir' determinados bienes o servicios con otros. Ha tenido que ser el propio Tribunal de Justicia de la UE el que tuviera que discernir qué es un servicio real de intermediación y, en consecuencia, desmitificar toda la construcción simbólica que se fue generando alrededor de este modelo que, más que extraer plusvalía, la aspira.

Previamente, la Audiencia Provincial de Madrid en 2017 ratificó la suspensión cautelar de UberPop en la certeza de que no se trata de un intermediario de transporte "sino que participa directamente en dicho servicio, incluso fijando el precio". La Audiencia Provincial afirmó que "la actividad de UberPop es la de una empresa de transporte que emplea su propia plataforma, fija los precios y dispone de multitud de conductores previamente seleccionados, sin que sea preciso en este caso determinar la relación que une a Uber con dichos conductores". Para la Audiencia no se trataría de un operador neutral, ni un mero operador tecnológico; "no puede acogerse a la exención de responsabilidad prevista para los servicios de la Sociedad de la Información". Y así, la sentencia del Tribunal de Justicia de la UE de 20 diciembre de ese mismo año declara que UberPop es una empresa de transporte y no una plataforma digital de intermediación entre viajeros. En consecuencia, se establece que "deben interpretarse en el sentido de que ha de considerarse que un servicio de intermediación, como el del litigio principal, que tiene por objeto conectar, mediante una aplicación para teléfonos inteligentes, a cambio de una remuneración, a conductores no profesionales que utilizan su propio vehículo con personas que desean efectuar un desplazamiento urbano, está indisociablemente vinculado a un servicio de transporte y, por lo tanto, ha de calificarse de servicio en el ámbito de los transportes, a efectos del artículo 58 TFUE, apartado 1. En consecuencia, un servicio de esta índole está excluido del ámbito de aplicación del artículo 56 TFUE, de la Directiva 2006/123 y de la Directiva 2000/31".

Los indicios que podemos observar de esta falsa economía colaborativa apuntan a un capitalismo de plataforma cuyo fin primario es el lucro y en el que tienen intereses megacorporaciones que han transformado en pocos años las listas de las mayores empresas del mundo (Galloway, 2017). Frente a posiciones cuyo fin es adaptar la regulación a la "nueva realidad" (Soria, 2017, p. 56), se encuentra la jurisprudencia mayoritaria de los tribunales de justicia donde se niega la condición de autónomo a alguien que es un asalariado (como en una sentencia de 4 de junio de 2018 del juzgado de lo Social número 6 de Valencia sobre un repartidor de Deliveroo). De hecho, el sindicato UGT cifró a finales de 2019 que las plataformas de reparto se ahorraban hasta 168 millones en salarios y cotizaciones.

El capitalismo de plataforma aprovecha las lagunas de una legislación insuficiente y perfectible. Los autónomos bien pueden terminar por convertirse en trabajadores por cuenta ajena, lo que constituye una amenaza para el sistema económico en su conjunto, ya que el salario mínimo representa una redistribución de la renta que mantiene la demanda interna (Todolí, 2017). La posición ventajista de estas empresas en cuestiones como la subcontratación significa aprovechar las oportunidades que brindan los cambios tecnológicos para ampliar las posibilidades de obtención de plusvalía, gracias a una actividad presuntamente colaborativa y altruista que es meramente lucrativa. El trabajo de los usuarios o rentas extraídas del propio usuario conforman un modelo, cuya tendencia evidente es la eliminación de derechos sociales y su sustitución por un sistema de puntuación regido por los likes. Esa liquidación supone ampliar la plusvalía.

Cuando el COVID19 generó una terrible pandemia global los repartidores de plataformas como Stuart, Deliveroo, Glovo y Uber Eats carecían de equipamiento para realizar su actividad y denunciaron ante la inspección de trabajo tener que realizarlo por lo que suponía incumplir el estado de emergencia, al no ser una actividad esencial.

Algunos pioneros de la Red pensaron que Internet permitiría superar la subordinación salarial, el empleo, reforzando el trabajo vivo y libre. Gracias a la creatividad y a unos medios de producción propios y fáciles de adquirir, el uso de plataformas en la Red generaría una cooperación que desafiaría la cultura capitalista. Las grandes empresas y fondos de inversión tenían planes diferentes. 


\section{La plusvalía en Red vs producción socialmente útil}

La noción tradicional de plusvalía permitía el análisis de relaciones laborales, La plusvalía en Red estudia la forma en que la fuerza social de trabajo, profundamente creativa y productora, es canalizada y disciplinada por el capital para su exclusivo beneficio. Internet como herramienta o plataforma de desarrollo cooperativo en común es deconstruida en favor de una gigantesca aspiradora de datos, que al cuando son procesados por grandes compañías se convierten en una mercancía tanto susceptible de plusvalía como un mecanismo de control como nunca se había visto en la historia. Se trata de una información valiosa para la creación de perfiles que pueden ser vendidos para anuncios o predicciones. El dominio se fortalece gracias al procesamiento de los datos.

Junto con la plusvalía, si algo debemos a Marx es su herencia profundamente humanista. Quizá sea Cornel West uno de los autores que mejor ha sabido reconocerla. West afirma que podemos encontrar ese profundo enfoque moral en la noción de alienación. Para Marx, sería un tipo de control y dominación en el que el dominado y controlado crea las condiciones para su propia deshumanización o cosificación (West, 1991). La cosificación de las relaciones sociales para convertirlas en mercancías negociables; la aniquilación de las relaciones significativas de las que nos habla Gil (1998) en su teoría sobre la justicia social, la repugnante conversión de los comportamientos humanos de colaboración o debate en un bien sujeto a monetización que termina en los balances de las grandes empresas del sector, que además no contribuyan a las haciendas de los estados, es la escandalosa dimensión de la plusvalía en Red. Todo ello, en un marco donde tanto la sentimentalización de relaciones mercantiles y la gestión gerencial de emociones personales y familiares hacen de los afectos un elemento más de la lógica neoclásica y la psicología positiva. En nuestro mundo, la democratización emocional ha allanado el camino para la subordinación gerencial y terapéutica (Rendueles, 2017).

El liberalismo había hecho bandera de la consecución de derechos individuales; hoy sirve para justificar la erosión sin precedente de estos, vinculado a la obtención masiva de plusvalía. La alianza con dictaduras o la erosión de principios básicos del Estado de derecho, con contratos de adhesión abusivos, se han naturalizado. Lo realmente decisivo para el modelo liberal ha sido y es servir de cobertura para la expansión del capitalismo. Los controles instaurados en el estado liberal, los checks and balances, pierden su fuerza, si es que alguna vez la pudieron ejercer con cierta solvencia. El proceso actual es de doble hélice: aspira la creatividad, el rastro de la ciudadanía, su trabajo y lo convierte en plusvalía; pero, al mismo tiempo, reconduce todo ese proceso hacia el control ciudadano que se convierte en una baza negociadora, en un capital sujeto a transacción con gobiernos $\mathrm{u}$ otros entes en una suerte de partnership a la que se refirió Miliband (2009) en su análisis del estado capitalista y que hoy se refuerza o se hace aún más evidente por la tecnología. Una suerte de omnipolitan cuyo fin es convertir las interacciones sociopolíticas en indistinguibles de las generadas en los mercados financieros (Virno, 2008, p. 75).

Con el capitalismo las necesidades humanas son fragmentadas y reorganizadas en diferentes esferas sociales, económicas e institucionales (Collective Design Projects, 1985). La relación entre producción y nuevas tecnologías ha fortalecido el control capitalista sobre la producción (GLC, 1985), lo que ha difuminado las fronteras entre vida social, personal y laboral, reidentificando al ser humano con su puesto en el mercado capitalista. Como señalaron los creadores de la producción socialmente útil, es en el proceso de producción donde se va a determinar la competitividad final del producto y los beneficios que dará. Lo que se produce, en qué cantidades determina la extensión y necesidades de las personas. El capitalismo ha logrado metabolizar la crítica a su modo de organización social, cultural y económica, estableciendo diferentes cebos propagandísticos y organizativos, que han mejorado su eficacia productiva sin modificar su esencia explotadora y acumulativa. Se presume una apuesta por la flexibilidad, la creatividad y la horizontalidad; sin embargo, lo que tenemos es un conjunto de manipulaciones que convierte a la ciudadanía en sujetos garantes del orden que han interiorizado, de acuerdo con pautas de comportamiento y necesidades vitales decididas por los poderosos con la finalidad de perpetuar relaciones de dominación (Boltanski y Chiapello, 2002).

¿Qué hacer? Una alternativa es una teoría de la justicia ligada a la democratización de la producción. Un paso en este sentido es la necesaria recuperación de la producción socialmente útil. La idea central de dicho modelo fue la producción colectiva de bienes o servicios socialmente necesarios. La producción capitalista no realiza un cuestionamiento democrático de la producción. La acumulación y la maximización del beneficio son los elementos que guían su acción. El concepto de producción socialmente útil engloba una serie de prácticas económicas que se propusieron y, en escasas ocasiones, se desarrollaron en Gran Bretaña, a finales de los setenta y principios de los ochenta (Rodríguez, 2005, 43-49). Algunas de ellas, como Lucas Aerospace, tuvieron una repercusión social muy importante. Esa experiencia se trasladó a la gestión económica del Greater London Council entre 1981 y 1986, año de su abolición por la Primera ministra Margaret Thatcher. Podría ser un ejemplo más para su aplicación contemporánea.

La experiencia de Lucas se desarrolló en un plan dividido en cuatro partes. La primera de dedicó a compilar documentación sobre los recursos de Lucas Aerospace; en la segunda se analizaron los problemas y necesidades a los que los trabajadores se enfrentaban en Lucas Aerospace como resultado de los cambios en la industria aeroespacial y en la economía mundial; en la tercera se valoraron las necesidades sociales que los recursos disponibles podían satisfacer; la última 
parte se dedicó a plantear propuestas detalladas sobre los productos, el proceso de producción y el programa de desarrollo del trabajo que contribuiría a cumplir diferentes necesidades (Wainwright \& Elliott, 1982). La crisis energética puso de manifiesto la importancia de concebir un medio de transporte que no contaminase. Sin embargo, en el mercado 'libre' no era posible satisfacer la demanda. Las implicaciones de este ejemplo y otros que presentaron los activistas de Lucas, revelaron que los productos no son tan sólo cosas. Su existencia y diseño son la consecuencia de propuestas y valores sociales que, a menudo, se ocultan (Lucas Aerospace Trade Union Committee, 1979). Los activistas de Lucas fueron influidos por los grupos pacifistas, por los feministas que desafiaban y criticaban la imagen que se daba de la mujer en la comercialización de muchos productos (como los cosméticos) y les asignaban rígidos papeles sociales. Otro grupo importante fue el movimiento antinuclear, que consideró las decisiones sobre política energética como valorables desde una óptica política y moral. Sin embargo, la novedad es que es necesario subrayar es el desafío que la iniciativa de los trabajadores de Lucas significó para la jerarquía de valores. Dicha jerarquía es impuesta desde la hegemonía totalizadora del sistema de producción capitalista. Ésta es la razón por la que su noción de producción socialmente útil se refiere no sólo a los productos, sino también al proceso de producción en sí.

La producción socialmente útil introduciría una suerte de deliberación en común en la economía, capaz de contextualizar las abstracciones argumentativas económicas capitalistas. Las lleva al terreno de lo que es necesario para la calidad de vida de aquellos que intervienen directamente en el proceso productivo y los que reciben sus bienes. Dentro de la idea de producción socialmente útil se engloba el debate sobre las formas de propiedad y control, las prácticas y procesos laborales, la satisfacción en el trabajo o el disfrute colectivo de los bienes producidos. Su aplicación a internet implica desligarse de las concepciones capitalistas de escasez o preferencias que convierten las necesidades humanas en mercancías. Las mercancías que prometen liberarnos se transforman en una forma de alienación, control y sometimiento (Collective Design/Projects, 1985). La traducción de esta vía se centraría en la gestión democrática del desarrollo tecnológico.

La dinámica que generaría la producción socialmente útil en Internet sería concerniente a la satisfacción de necesidades sociales, gracias a las posibilidades tecnológicas que se podrían encauzar para fines comunes. En consecuencia, se atendería a todas las fases del proceso productivo, a sus canales, a su diseño y a su materialización. Las empresas podrían aprovechar las mejoras tecnológicas en el marco de una jerarquía de valores alternativa a la capitalista, potenciando la cooperación y el intercambio de conocimiento. Precisamente, uno de los graves problemas del modelo económico y cultural hegemónico es paralizar y bloquear la mejora de los productos y los avan- ces tecnológicos y científicos. Un mercado diverso, no concentrado, donde se privilegie la cooperación y los productos respondieran a la utilidad social generaría fuertes sinergias que producirían avances tecnocientíficos, pero sobre todo humanos.

El capitalismo realmente existente es un freno a la creatividad y al desarrollo. El desmedido poder de las finanzas cierra la puerta al crecimiento de buenas ideas y empresas solventes. Fueron precisamente estas grandes empresas las que fueron incapaces de ver las potencialidades de Internet y de apostar por ello en los inicios de la Red de redes. No hace falta ser un visionario para concluir que, de haber existido un ecosistema neoliberal en esa época, el desarrollo de la Red se hubiera entorpecido mucho. La producción socialmente útil no defiende una planificación centralizada y estatal, sino una organización común desarrollada democráticamente por la propia sociedad que implica a las personas como productoras orientadas a la satisfacción de necesidades sociales y la colaboración. Con las nuevas tecnologías de la información se pueden detectar necesidades insatisfechas y establecer vías eficaces de autogestión y la autonomía de los productores que conecten con los usuarios de sus servicios. Una economía de código abierto, flexible, ágil y que descanse en la democratización de la producción, libre de plusvalías y fuertemente creativa.

\section{Conclusiones}

Paulo Freire afirmó que "decir que los hombres son personas, y como personas son libres, y no hacer nada para lograr concretamente que esta afirmación sea objetiva, es una farsa". En la sociedad capitalista, se recurre constantemente a la libertad para amparar metafísicas que matan, como la mano invisible, sin sustento con la realidad material. Sin embargo, se repara muy poco o nada en cómo ejercerla.

La escuela se puede transformar en un vivero de datos para una megaempresa transnacional y nuestros hijos en meros objetos que generan dólares. La ciudadanía puede transformarse tanto en una mina de datos sobre los que negociar, como súbditos sujetos a la vigilancia y control de gobiernos y corporaciones privadas.

¿Vamos hacia un modelo tecnototalitario? No es una cuestión ociosa. Internet es un campo de batalla donde se desarrollan procesos y tendencias liberadores o totalitarios; privatizadores o comunes. Esta lucha va camino de transformarse en guerra si las tendencias de vigilancia, control y liquidación de derechos fundamentales que se atisban con el COVID19 se consolidan. No se trata de ser apocalípticos o integrados, sino de entender que la salida de las crisis implica una toma de decisiones y si, por miedo o conformismo, cedemos nuestra palabra a unos pocos, los resultados serán beneficiosos para ese reducido sector de la población. En ese sentido, vincular la Red a prácticas comunes y repensar la producción de forma democrática y socialmente útil, sería la forma de construir la democracia. 


\section{Referencias}

Baran, P. A. y Sweezy, P. M. (1980). El capital monopolista. México: Siglo XXI.

Boltanski, L., Chiapello, E. (2002). El nuevo espiritu del capitalismo. Madrid: Akal.

Collective Design/Projects (ed.) (1985). Very nice work if you can get it. The socially useful production debate. Notthingham: Spokesman.

Crary, J. (2015). 24/7. El capitalismo al asalto del sueño. Barcelona: Ariel.

Dyer-Witheford \& Matviyenko, S. (2019). Cyberwar and Revolution. Digital Subterfuge in Global Capitalism. Minneapolis: University of Minnesota Press.

Eco, U. (1988). Apocalípticos e integrados. Barcelona: Lumen.

Fuchs, C. (2019). Reading Marx in the age of digital capitalism. London: Pluto Press.

Galloway, S. (2017). The Four. The hidden DNA of Amazon, Apple, Facebook and Google. London: Bantam Press.

Gil, D. (1998). Confronting injustice and oppression. Concepts and strategies for social workers. New York: Columbia University Press.

GLC (1985). The London Industrial Strategy. London: GLC.

Hardt, M. \& Negri, A. (1994). Labor of Dionysus. A critique of the State-Form. Minneapolis: University of Minnesota Press.

Hardt, M. y Negri, A. (2004). Multitud. Guerra y democracia en la era del Imperio. Barcelona: Debate.

Harman, C. (2018). La otra historia del mundo. Una historia de las clases populares desde la Edad de Piedra al nuevo milenio. Madrid: Akal.

López, G. (2019). ¿De quién es la economía colaborativa?, Rebelión. Otro mundo es posible. Recuperado en https://rebelion.org/ de-quien-es-la-economia-colaborativa/.

Lucas Aerospace Trade Union Committee (1979). Turning industrial decline into expansion. A Trade Union initiative. London: Lucas Aerospace Trade Union Committee.

Luxemburg, R. (1967). La acumulación de capital. México: Grijalbo.

Marx, K. (1977). El Capital. London: Progreso.

Marx, K y Engels, F. (2011). Manifiesto comunista. Madrid: Alianza Editorial.

Mason, P. (2015). Postcapitalism: a guide to our future. London: Penguin Books.

Miliband, R. (2009). The State in capitalist society. London: Merlin Press

Montero Pascual, J. J. (coord.) (2017). La regulación de la economía colaborativa: Airbnb, BlaBlaCar, Uber y otras plataformas. Valencia: Tirant Lo Blanc.

Rendueles, C. (2017). La gobernanza emocional en el capitalismo avanzado. Entre el nihilismo emotivista y el neocomunitarismo adaptativo. Revista de Estudios Sociales, 62, 82-88. https://dx.doi.org/10.7440/res62.2017.08.

Rodríguez, J. C. (2013). De qué hablamos cuando hablamos de marxismo. (Teoría, literatura y realidad histórica). Madrid: Akal.

Rodríguez Prieto, R. (2019). Retos jurídico-políticos de Internet. Madrid: Dykinson.

Rodríguez, R., Martínez, F. (2016). Poder e Internet. Un análisis crítico de la Red. Cátedra: Madrid.

Rodríguez Prieto, R. (2005). Construyendo democracia. Una propuesta para el debate. Sevilla: Aconcagua.

Santos, M. (2000). La naturaleza del espacio. Técnica y tiempo. Razón y emoción. Barcelona: Ariel.

Soria. B. (2017). Aspectos económicos de la economía colaborativa. En La regulación de la economía colaborativa: Airbnb, BlaBlaCar, Uber y otras plataformas (J. J. Montero Pascual, pp. págs. 67-85). Valencia: Tirant lo Blanch.

Srnicek, N. (2016). Platform capitalism (theory redux). Cambridge: Polity Press.

Sundararajan, A. (2016). The sharing economy. The end of employment and the rise of crowd-based capitalism. Cambridge: MIT Press.

Todolí Signes, A. (2017). El trabajo en la era de la economía colaborativa: la clasificación jurídica de trabajadores y autónomos y los efectos de la reputación online en la economía de las plataformas virtuales. Valencia: Tirant lo Blanch.

Virno, P. (2008). Open sky. New York: Verso.

Virno, P. (2003). Virtuosismo y revolución. La acción politica en la era del desencanto. Madrid: Traficantes de sueños.

VV. AA. (2019). Temas clave de la filosofia del Derecho y politica. Madrid: Tecnos.

Wainwright, H. \& Elliott, D. (1982). The Lucas Plan. A new trade unionism in the making? London: Allison \& Busby. 